framework within which public support for industrial research as distinct from the kind of research which the research councils carry out should be undertaken. But these are small parts of the government's interest in research and development.

Last year, defence research accounted for 40 per cent of all government expenditure on research and development and although the proportion has been falling steadily for several years, it is hard to think it wise for expenditure on such a scale to continue much longer without a thorough investigation of the principles on which the money should be allocated to different causes. The result of all this, of course, is the paradox that while the scientific community in Britain has its interest chiefly engaged in an important but essentially organizational question about the best way of allocating funds to one part of publicly supported civil research, the government is perpetrating policy decisions about the scale of its involvement in research and development as a whole in the years ahead which have serious consequences for the scientific community and which may even be unwise as well.

\section{Fishing in European Waters}

FISHERMEN are understandably among the most vociferous and conservative members of any community, which is no doubt why it has taken such a time for the government now seeking membership of the European Communities to reach an understanding on fishing policy. On December 12, the representatives of Britain, Ireland and Denmark seem to have reached an accommodation with Brussels on a fishing policy for the next decade, but the government of Norway will come back next year to resume negotiations which are plainly turning out to be so complicated that Norway may yet finish up outside the European Communities. For the remaining countries, the new agreement on fisheries is in fact more than generous.

Unhappily, there is nothing in this agreement to ensure that the decade ahead will be one in which fish in northwest Europe are free from the pressures of over-fishing which are at present a far greater danger to their survival than any other influence. In the years since the Second World War, herring have been seriously damaged by overfishing, which is why it is encouraging that the North-East Atlantic Fisheries Commission apparently agreed at its meeting in Moscow last week to impose not merely a closed season on herring fishermen but also restrictions on the permissible catch as well. Only time will tell if these new proposals will be less toothless than the regulations with which the International Whaling Commission has failed to protect blue whales in the South Atlantic, but there is always room for hope.

The long haggle in Brussels over the precise regions of the European coast to be fished by vessels of different nationalities has more acutely drawn attention to the folly of attempts to conserve the stocks of fish in the waters off north-west Europe by the arbitrary methods now sought. A part of the trouble, of course, is that even the agreed twelve mile limit does not necessarily contain all the breeding grounds where most damage might be done by over-fishing. If it is intended that there should be a European fisheries policy, it should at least cover the whole of the North Sea and those parts of the Western
Approaches which are accessible to rational study. The second difficulty which has emerged in the past few months is that very little is known of the biology underlying the productivity of the European fisheries. Is it possible, for example, that the remarkable increase in the numbers of young haddock and whiting in the North Sea within the past decade is to be linked with the way in which the herring have declined in the same period? The species do not compete for a common food supply but there may be other influences at work. And why is it that the Plymouth herring has chosen this time to return in strength? Is there some secular change of climate? Is it possible that pollution, on the moderate scale on which organic nutrients find their way into the North Sea and similar basins, is actually a help and not a hindrance? These are all questions which need to be much more adequately understood before a permanent fisheries policy is negotiated, and for this reason it is entirely welcome that $\mathrm{Mr}$ Geoffrey Rippon should have told the House of Commons last week that he had urged on the European Communities "the need for common action in all our interests to ensure conservation of stocks". Unhappily, so far as can be told from government departments, Mr Rippon has no specific proposals for setting up machinery to regulate fisheries on a European basis. It is to be hoped that he and his colleagues will not wait for the whole decade before clearing their minds.

\section{Years Ago}

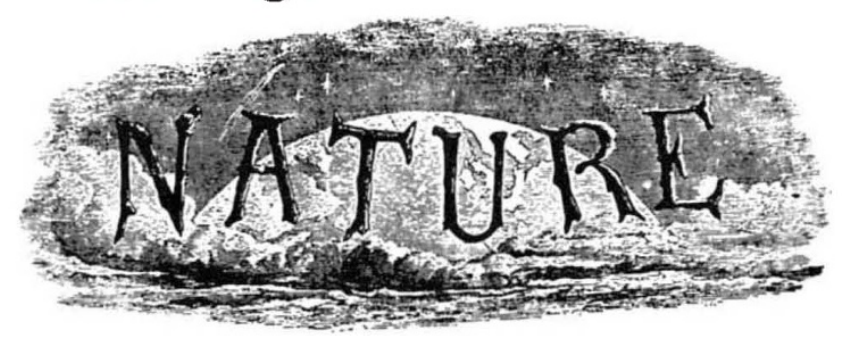

MANCHESTER

Literary and Philosophical Society, November 28.Dr. J. I. Joule, F. R.S., vice-president, in the chair." "Encke's Comet and the Supposed Resisting Medium," ly Professor W. Stanley Jevons. The observed regular diminution of period of Lincke's comet is still, I believe, an unexplained phenomenon for which it is necessary to invent a special hypothesis, a Dirs ex machinu, in the shape of an imaginary resisting medium. I cannot be sure that the suggestion $I$ an about to make has not already bcen made, but I have never happened to meet with it ; and therefore I venture to point out how it seems likely that the retardation of the comet may be reconciled with known physical laws. It is asserted by Mr. R. A. Proctor, Prof, Usborne Reynolds, and possibly others, that comets owe many of their peculiar phenomena to electric action. I need not enter upon any conjectures as to the exact nature of the electric disturbance, and I do not adopt any one theory of cometary constitution more than another. I merely point out that if the approach of a comet to the sun causes the development of electricity arising from the comet's motion, a certain resistance is at once accounted for. Wherever there is an electric current, some heat will be prorluced and sooner or later radiated into space, so that the comet in each revolution will lose a small portion of its total energy. In the experiments of Arago, Joule, and Foucault, the conversion of mechanical energy into heat by the motion of a metallic body in the neighbourhood of a magnet was made perfectly manifest. If then there is any magnetic relation whatever between the sun and the comet, the latter will certainly experience resistance. The question is thus resolved into one concerning the probability that a'comet would experience electric disturbance in approaching the sun. On this point we have the evidence now existing that there is a close magnetic relation between the sun and planets. If, as is generally believed, the sun-spot periods depend on the motion of the planets, a small fraction of the planetary energy must be expended.

From Nature, 5, 174, December 28, 1871 